Mutsumi Ohira

Kyoto Sangyo University

\title{
Teacher Support for Subject Study in School Libraries: A Case Study on the Faculty for Teachers for Subject Learning in School Libraries in Japan
}

\section{Introduction}

Although school libraries are found in all elementary, middle, and high schools in Japan, 40\% of schools nationwide have 11 classes or fewer wherein the appointment of librarians has been suspended currently; moreover, 6,838 schools have neither appointed nor assigned school librarians. Subject learning necessitates collection and usage of appropriate materials and requires specialization in the school education system, such as the use of curricula. Proper staffing alone is not adequate to resolve these issues. For the contemporary world with rapidly developing information devices, this paper proposes school library management methods involving improvements such as the use of reference devices by employing information and communication technology (ICT) and artificial intelligence (AI), which is not limited to personnel assignment, through investigation into the roles played by the human staff.

Keywords: teacher support, subject learning, school librarians

\section{Statement of the Research Problem}

This study specifies the materials, staff roles, and environment essential for school libraries to reform the existing system, with a focus on reading, and to construct a school library that helps teachers to improve their lectures for their students' independent study.

\section{Literature Review}

Vygotsky states that "the actual development level (the everyday concepts acquired by the child's action [behavior] toward the exterior) and the adults' scientific concepts are blended through social interaction (communication) between them, thereby reshaping these everyday concepts to attain a higher level (proximal development level)." I believe that providing teacher support in school libraries will lead to improvements in the quality of students' subject learning.

\section{Methodology}

In collaboration with Takayama City and Wakayama Prefecture, I investigated the appointment of school librarians, examined what the teachers provide as their subject instructions (i.e., offered materials and locations, cooperation with other institutions, and team teaching), and categorized 
the results. Involvement with classes utilizing their school libraries from the planning stages enabled consideration of the information leading to class improvement in each grade and subject unit, and this efficacy was reviewed after each class. The main causes of issues arising when teachers utilized their school libraries were clarified, and survey analysis of the role of the school libraries was conducted.

\section{Findings}

In Takayama City (Gifu Prefecture), where school librarians are assigned at all municipal elementary and middle schools, I surveyed subject learning that made use of the school libraries (September 1, 2019-January 31, 2020). Over the course of the investigation, I observed that subject learning was being presented predominantly by the Japanese language departments largely in relation to reading.

\section{Discussion}

Economic disparity is often said to be educational disparity. Equal opportunities in educational and learning activities must be maintained in public schools. School libraries should be open resources in all schools, and they should provide information to all students and teachers. However, at present, there are regional disparities in school libraries due to the financial circumstances of the local governments. Here, I consider the construction of a society in which differences in the size and financial circumstances of the local governments should not lead to disparities in the use of the school libraries.

\section{Implications and Conclusions}

School libraries are still only rarely used for subject learning in Japan because lecture-type classes remain the focus of Japanese school education wherein the courses of study and government-approved textbooks play a vital role. In 2020, ICT and programming education are being introduced in school curricula, and there has been a shift in the types of education wherein independent learning can be realized. Libraries must be designed to enable the use of a diverse range of information and to support the students and teachers doing so.

\section{References}

Ministry of Education, Culture, Sports, Science and Technology. (2016). Survey on the current state of school libraries. https://www.mext.go.jp/a_menu/shotou/dokusho/link/1378073.htm

Takatori, K. (1994). Vygotsky, Piaget, and the development of activity theory. Kyoto Hosei Publishing.

Vygotsky, L. S. (1978). Mind in society: Development of higher psychological processes. Harvard University Press. 